\title{
The legacy of Ladislau Steiner (1920-2013): the neurosurgeon who won the heart of the world
}

\author{
Ad astra per aspera
}

\author{
D. A. Nica • D. Mohan • H. Moisa • A. V. Ciurea
}

Received: 8 February 2014 / Accepted: 9 February 2014 / Published online: 28 February 2014

(C) Springer-Verlag Berlin Heidelberg 2014

There are not many things one can say when the tragic moment of losing a friend and a mentor comes. Professor Ladislau Steiner was, first of all, more than just a friend and a mentor. He was a man from which all of us, those who knew him, had a lot to learn both professionally and in what regards life conceptions, appreciating true value, simply talking to a patient, holding a speech, and so on. As time passed, Professor Steiner became our role model; he became a symbol of virtue and commitment to medicine. Like all great neurosurgeons, although he is no longer physically amongst us, his spirit is above, watching (Image 1).

Born on the 26th of August 1920 in one of Transylvania's iconic fortress cities - the city of Fagaras (Image 2) Professor Ladislau Steiner was part of the team that invented and promoted Gamma Knife Radiosurgery. He lived his talelike childhood not far from the famous monastery of Sambata which was erected by the martyr Constantin Brancoveanu as a symbol of Orthodox Christianity in Transylvania.

His proper upbringing and education made him stand out as a bright and hard-working student ever since his admission in high school which he graduated top of his class.

D. A. Nica

Department of Neurosurgery, St. Pantelimon Emergency University

Hospital, Bucharest, Romania

D. Mohan

Department of Neurosurgery, Bihor County Emergency University Hospital, Oradea, Romania

H. Moisa $\cdot$ A. V. Ciurea $(\bowtie)$

Department of Neurosurgery, "Carol Davila" University School of

Medicine, Bucharest, Romania

e-mail: prof.avciurea@gmail.com

A. V. Ciurea

Department of Neurosurgery, "Sanador Medical Center" Hospital,

Bucharest, Romania
Soon after high school, the future doctor L. Steiner gets admitted at the King Ferdinand University, Medical School in Cluj-Napoca. At the time, the medical school was renowned for the elite group of professors which were active in all the fields of medicine.

For example, the chair of anatomy was Professor Victor Papilian (1888-1956), at histology was Professor A. Miskolcy (1894-1978), at internal medicine was Professor Iuliu Hatieganu (1885-1959) (after which the university was later baptized), and last but not the least, the chair of surgery was Professor Iacob Iacobovici (1879-1959), one of the most famous surgeons in Eastern Europe at the time.

Using the advantages such an exquisite academic environment had to offer, the young Ladislau Steiner manages to publish a few studies concerning conditional reflexes during experimental traumatic brain injuries and the modifications of the CSF during schizophrenia and epilepsy. His early works proved that the young medical student had a special set of skills needed for research and deep understanding of neurosurgery.

His early certified neurosurgical activity arrived during the pioneering age of the Cluj-Napoca clinic of neurosurgery, at the time of which there still were countries in Europe that did not have an autonomous neurosurgical unit. His first mentor, Prof. Stefan T. Iacob (1920-1975), managed to keep young Ladislau interested in neurosurgery, while at the same time helping him get the bigger picture in international medicine. It was in Cluj where Ladislau learned that success is obtained only through commitment and hard work.

Eager for knowledge, Ladislau gets admitted to a short stage of neurosurgery in the clinic of Prof. Constantin Arseni (1912-1994) in Bucharest in 1960 and soon afterwards leaves together with his wife Melita for a short period of time to Prof. Friedrich Weickmann's clinic in Berlin Buch.

Through a fortunate twist of events, Ladislau and his wife Melita manage to leave the Soviet Bloc through checkpoint 


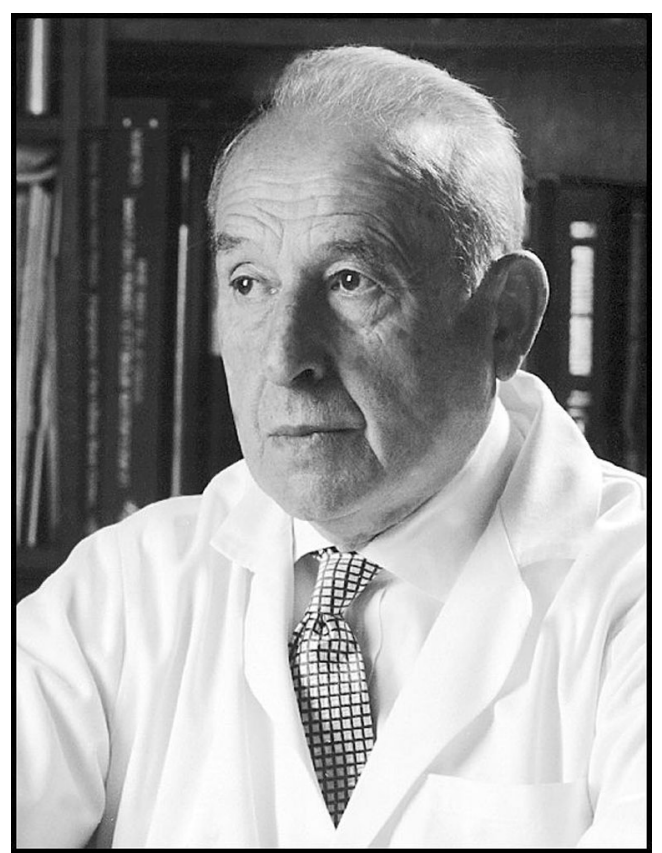

Image 1 Professor Dr. Ladislau Steiner

Charlie and arrive in 1962 at the mecca of neurosurgery-the Karolinska Institute in Sweden (Image 3).

The young Ladislau committed himself to neurosurgery in a completely new language and launched himself into a 25year-long adventure which culminated with the Royal decree granting him the position of head of the second department of neurosurgery at the Sophia Hemmet Institute. Steiner was only one of the famous neurosurgeons schooled by the wellknown Professor H. Olivecrona (1891-1980).

His $\mathrm{PhD}$ thesis which approached in 1975 "The mechanism of death in subarachnoid hemorrhages" was an experimental study which was widely appreciated due to its highly sensitive nature concerning the vascular pathology frequent in the Scandinavian countries.

Together with Nobel Laureates Sune K. Bergstrom (19162004) and Bengt Samuelson (1934-), Steiner conducted a

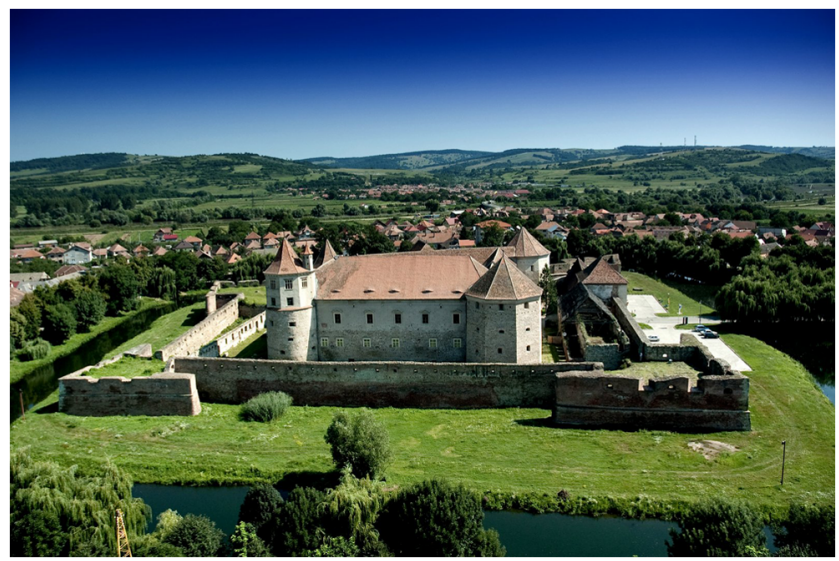

Image 2 The fortress of Fagaras (Steiner's hometown)

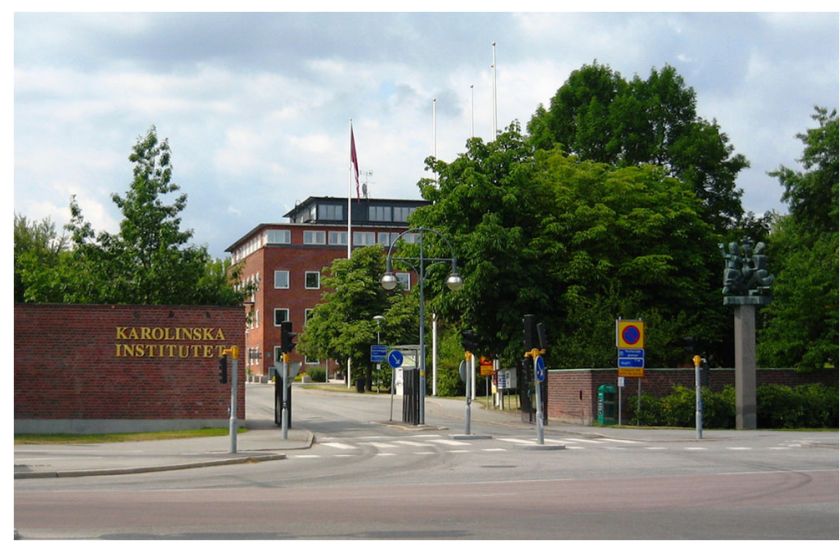

Image 3 The Karolinska Institute

wide series of tests concerning prostaglandins and other inflammatory molecules and furthermore a series of tests concerning mechanisms of immune response in intracranial gliomas.

The creativity of Professor Lars Leksell (Image 4.) got the attention of Steiner who immediately saw the importance of its application in the treatment of intracranial expansive processes. Together with Leksell, Steiner published the first articles about the results of Gamma Knife Surgery in arteriovenous malformations, acoustic neuromas, and craniopharyngiomas [1-6].

After his departure from the Karolinska Institute, Professor Steiner was appointed Alumni Chair and Professor of Neurosurgery and Radiology as well as the Director of the Lars Leksell Center for Gamma Knife Radiosurgery at the University of Virginia in the USA. He also became official neurosurgical consultant for the European Hospital in Rome, Italy. At his new location in the US (see Image 5), Professor

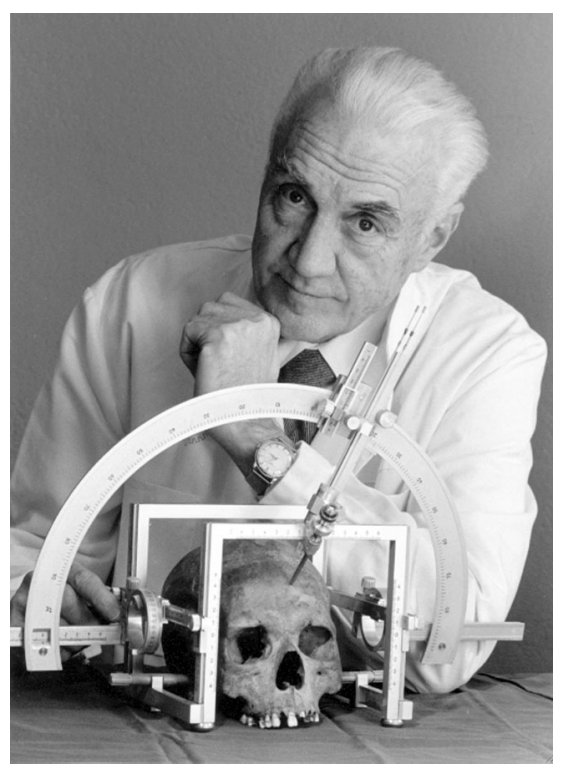

Image 4 Professor Lars Leksell 


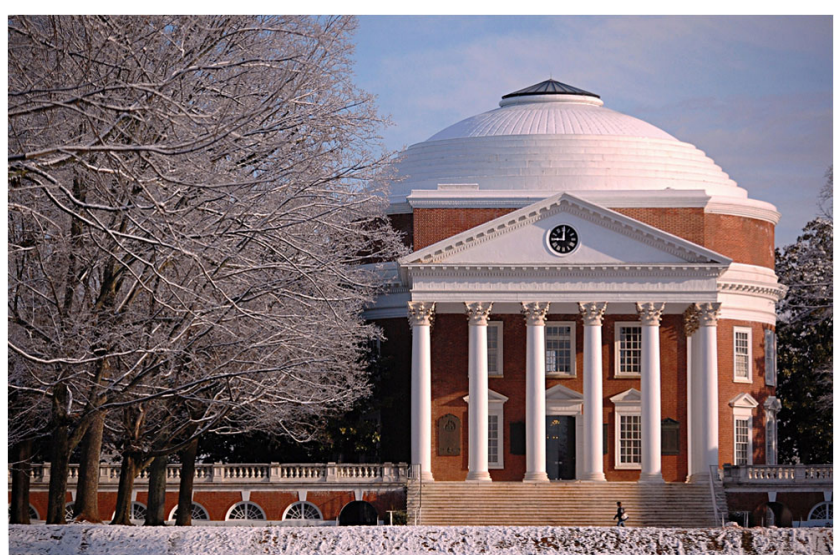

Image 5 The University of Virginia Rotunda

Steiner worked until 2010 and conducted about 15.000 Gamma Knife interventions for patients from 57 countries and 6 continents.

He managed to clearly illustrate the indications, advantages, and disadvantages of this new means of treatment and often criticized the wrong usage of GKS by different authors. The yearly courses organized by Professor Steiner under the name of "The Lars Leksell Lectures" at the University of Virginia are well-known and were appreciated worldwide.

Besides being one of the inventors of Gamma Knife surgery, Professor Steiner also got committed in the development of the first hemostatic titanium clip (together with van Holst), a guide for the use of lasers in stereotactic neurosurgery and methods of reconstruction of the Sylvian aqueduct.

In July 2010, after leaving the University of Virginia, he accepts Prof. Madjid Samii's invitation to be Professor of Neurosurgery and chief of Gamma Knife Radiosurgery at the International Neuroscience Institute in Hannover, Germany, where he worked until February 2013 (Image 6).

A true Romanian, as himself stated, Professor Steiner manifested his intentions to help Romanian neurosurgery as soon

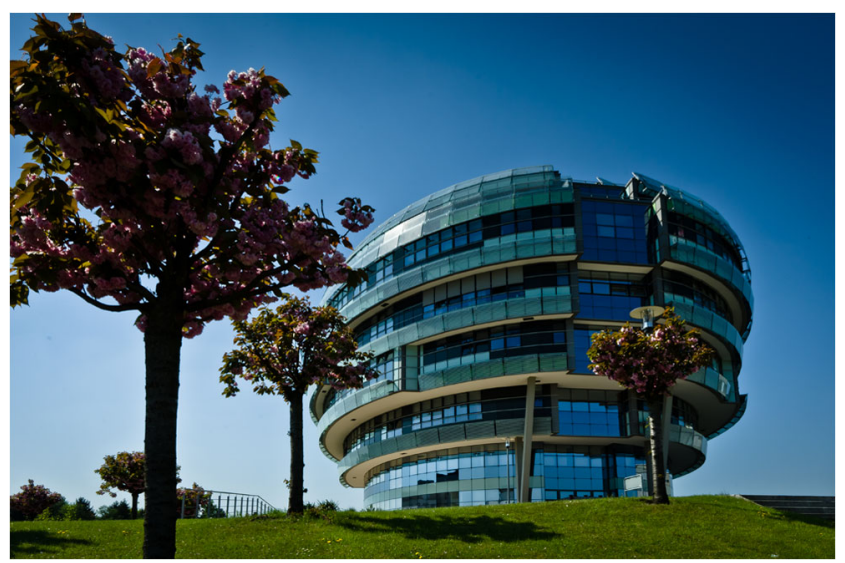

Image 6 INI Center, Hannover, Germany (source for Image 6: http:// galerie.chip.de/k/architektur/architektur/ini/808791) as the communist regime in Romania was abolished. In Acapulco in 1993, during the tenth congress of the WFNS, Professor Ladislau Steiner was invited by Professors Al. Constantinovici and A. V. Ciurea to participate at the upcoming congress of Romanian Society of Neurosurgery in Timisoara (Romania) which was held in 1994.

Professor Steiner was more than happy to participate and presented a study entitled "Clinical and angiographic outcome in patients with aneurysms after surgery-a long term follow up" and another study "Gamma Knife Radiosurgery in vascular lesions of the brain. Facts and fiction." From that moment, Professor Steiner won the hearts of his Romanian fellow surgeons and was regarded as a true mentor in neurosurgery and Gamma Knife Radiosurgery. It was due to Professor Ladislau Steiner's efforts that in 2003 Romania was the first country in Southeastern Europe that managed to operate a completely autonomous Gamma Knife Surgery unit at the National Center for Excellence in Neurosurgery in Bucharest.

Professor Steiner's continuous change of ideas with his Romanian peers meant a constant accelerated progress for the neurosurgical field in Romania which had a lot to suffer due to the communist regime. A warmhearted man, Professor Steiner always had kind words to address his younger Romanian pupils and always found the patience to teach them new tricks regarding this challenging field of medicine.

He always was a true friend of the Romanian Society of Neurosurgery being the first one to internationally promote the first Black Sea Congress of Neurosurgery (1995, Mamaia) and the first Danube-Carpathian Congress of Neurosurgery (2010, Cluj-Napoca). As a testimony of his true Romanian soul, his last public appearance was in his home country in September 2012 where his warm speech, as usual, caught the attention of everyone attending the International Congress of the Romanian Society of Neurosurgery.

The number of medals, letters of recognition, and international titles that were bestowed upon Professor Steiner is only an understatement regarding his true value as a neurosurgeon, as a professor, and as a man. Professor Steiner was Sheline Professor at the University of California in San Francisco (UCSF) and Lars Leksell Lecturer at the Karolinska Institute (2001); he received the Sugita award from the International Society for Neurosurgical Technology and Instrument Invention, the Medal of Honor from the World Federation of Neurosurgical Societies (2003), Honorary President of the Romanian Society of Neurosurgery, and many others.

His successful activity as a scientist has lead to the birth of more than 370 articles which appeared in some of the most well-known journals in the world. We feel obliged to mention the fact that in 2012 and 2013 alone, we are familiar with an important number of papers approaching cancer research, genetics, stereotactic radiosurgery, and arteriovenous malformations $[7,8]$. 
During his lifelong activity in neurosurgery, he was constantly supported by Dr. Melita Steiner (his beloved wife) without whom his "modest" contribution for neurosurgery had not been possible. They had two children, Michael and Eugen. One of them became a doctor; the other became a mathematician. Professor Steiner passed away a year ago in February of 2013 leaving behind him an enormous legacy in neurosurgery and Gamma Knife Surgery which turns his personality to a modern-day legend of neurosurgery just like H. Cushing, G. Yasargil, or M. Samii.

"We have lost not only an outstanding neurosurgeon but also a very good friend, who has received the highest recognition for his life achievements during the last decades." (M. Samii)

Dumnezeu sa-l odihneasca in pace dupa sufletul sau bunmay he rest in peace after his good soul (Romanian saying).

\section{References}

1. Steiner L, Leksell L, Greitz T, Forster DM, Backlund EO (1972) Stereotaxic radiosurgery for cerebral arteriovenous malformations. Report of a case. Acta Chir Scand 138:459-464

2. Steiner L, Leksell L, Forster DM, Greitz T, Backlund EO (1974) Stereotactic radiosurgery in intracranial arterio-venous malformations. Acta Neurochir (Wien) 21:195-209

3. Dahlin H, Larsson B, Leksell L, Rosander K, Sarby B, Steiner L (1975) Influence of absorbed dose and field size on the geometry of the radiation-surgical brain lesion. Acta Radiol Ther Phys Biol 14: 139-144

4. Steiner L, Forster D, Leksell L, Meyerson BA, Boëthius J (1980) Gammathalamotomy in intractable pain. Acta Neurochir (Wien) 52: 173-184

5. Leksell L, Lindquist C, Adler JR, Leksell D, Jernberg B, Steiner L (1987) A new fixation device for the Leksell stereotaxic system. Technical note. J Neurosurg 66:626-629

6. Heppner PA, Sheehan JP, Steiner L (2005) Gamma Knife Surgery for low grade gliomas. Neurosurgery 57:1132-1139

7. Schwyzer L, Yen CP, Evans A, Zavoian S, Steiner L (2012) Long-term results of gamma knife surgery for partially embolized arteriovenous malformations. Neurosurgery 71(6):1139-1147, discussion 1147-8

8. Steiner L, Steiner M (2013) Closed focus beam neurosurgery: variation on a theme. World Neurosurg 78:1944-1945

\section{Comments}

Helmut Bertalanffy, Hannover, Germany

At the end of February 2013, I learned with great sadness that Professor Steiner has left us forever. While I have first met him many years ago, it was only during his last 2 years of life (2011-2012) that we became closer to each other here at INI Hannover. I had many exciting conversations with Laszlo about his life, his first years of work in Stockholm, and about Herbert Olivecrona and Lars Leksell. With his unique way of communicating with others, he never let coming up a feeling of age difference between us, although this difference is of one generation. Like everybody at our institute, I liked and admired Laszlo for his never fading, deep interest in patient care and the way he continued managing numerous patients from various countries, some of whom he might have first treated decades ago. We also liked him for many other reasons, among them his deep humanity, his seriousness, and his sincerity, and certainly, we all respected him deeply for his outstanding life work in neurosurgery. We will not forget the wonderful dinner he hosted for the INI members in 2012 when he gave an impressive lecture in old Swedish tradition. We painfully miss him here in Hannover.

Amir Samii, Hannover, Germany

I would like to express my sincere appreciation and thanks to Professor Ciurea and his co-authors for having prepared this article in the honor of Prof. Steiner.

The neurosurgical community respects Prof. Steiner for his outstanding contributions to our field, which beyond any doubts have their special place in the history of neurosurgery.

I had the privilege of meeting Prof. Steiner the first time in 1989 at a meeting in Athens. I was still a medical student and far from understanding the significance of this legend of neurosurgery. Still, I was immediately impressed by his personality, which was characterized by sharpness of thought, modesty, cordiality, and wisdom. Indeed a rare combination! Over the last two decades, this impression was again and again reconfirmed at every single occasion at which I would meet him. After the 10-year anniversary celebration of our institute in June 2010, he gave all of us at INI the privilege to accept joining us and continuing his work at INI. Shortly after he arrived in August 2010 in Hannover, my parents and my wife Inga were celebrating his 90th birthday with him. At this occasion, my wife asked him why he came to Hannover. He simply replied to her, "I thought at the age of 90 it is time to re-define myself." We were all truly baffled. During the following 2 years, it was a real privilege to work next to a living legend. In many very personal conversations with Laszlo, I have not only learned tremendously about life in general and about philosophy in neurosurgery, but I have also learned about dignity in every sense of this word. Besides his brilliant intellectual skills and the constant challenge of thoughts, he was a philanthropist trying to please the people around him. His place can never be filled, and we will always miss him. 